\title{
Functional and radiological outcome of surgical treatment of distal tibial fracture by minimally invasive percutaneous plate osteosynthesis technique
}

\author{
Shobha H. P., Karthik S.*, Akshay Dhanda, Lingaraju K., Giridhar Kumar
}

Department of Orthopaedics, Mysore Medical College and Research Institute, Mysore, Karnataka, India

Received: 08 December 2019

Revised: 04 February 2020

Accepted: 10 February 2020

\section{*Correspondence:}

Dr. Karthik S.,

E-mail: karthik.panja@gmail.com

Copyright: () the author(s), publisher and licensee Medip Academy. This is an open-access article distributed under the terms of the Creative Commons Attribution Non-Commercial License, which permits unrestricted non-commercial use, distribution, and reproduction in any medium, provided the original work is properly cited.

\begin{abstract}
Background: Minimally invasive percutaneous plate osteosynthesis (MIPPO) is an established technique for fixation of fractures of the distal third tibia. Aim of our study was to manage extraarticular fractures of the distal third tibia by the minimally invasive plate osteosynthesis technique and follow them prospectively. Clinical and radiological outcomes were studied and clinical indications \& efficacy of the procedure reviewed.

Methods: From June 2018 to June 2019,25 patients of closed distal tibial fractures were operated by MIPPO technique with a distal tibial anatomical locking plate having 4.5 out of 5 proximal and 3.5 out of 4 distal screw holes. The follow up duration was for 1 year.

Results: The mean fracture healing time was 17 weeks (range 16 to 32 weeks) and average The American orthopedic foot and ankle score was 88.2 out of a total possible 100 points. At last follow up, superficial infection occurred in 3 patients, deep infection in 1 patient, ankle stiffness in 1 patient, limb length discrepancy $<1 \mathrm{~cm}$ in 1 patient and malunion in 2 patients.

Conclusions: MIPPO technique provides good bone healing and decreases incidence of non-union and need for bone grafting. This technique should be used in distal tibia fractures where locked nailing cannot be done like fractures with small distal metaphyseal fragments, vertical splits, markedly comminute fractures.
\end{abstract}

Keywords: Distal tibia fracture, Locking compression plate, Percutaneous plating, Distal tibia fractures

\section{INTRODUCTION}

Fractures of distal tibia constitute $10 \%$ of all lower extremity fractures. ${ }^{1}$ These fractures are unique and challenging to manage because the bone is subcutaneous with depleted muscular cover, the consequent decreased vascularity leads to complications like delayed bone union, wound complications such as dehiscence and infection when treated with open reduction internal fixation. Non operative treatment is not an option anymore as it may be associated with joint stiffness in up to $40 \%$ of cases as well as shortening and rotational malunion in over $30 \%$ of cases. ${ }^{2}$ Due to proximity of these fractures to the ankle, regaining full ankle movement may be difficult in non operative management.

With operative treatment shortening and other complications associated with prolonged immobilization can be avoided. ${ }^{3}$ Open reduction internal fixation (ORIF) have been performed for distal tibial fractures and is associated with complications like infection and delayed or non-union due to dampened blood supply to bony 
fragments and also additional damage to soft tissue. ${ }^{4}$ Soft tissue management plays a vital role in management along with bony reconstruction. There are plenty of devices available for fixation, including intramedullary nail, extramedullary traditional plate and the relatively new precontoured $3.5 \mathrm{~mm}$ distal locking compression plates. Locking compression plate (LCP) provides better stability and protection against loss of reduction and minimizes contact with bone. ${ }^{5,6}$

Minimally invasive percutaneous plate osteosynthesis (MIPPO) technique preserves the fracture hematoma, decreases the soft tissue damage and reduces damage to bone vascularity. ${ }^{7}$ Thus taking a lot of above mentioned problems, this philosophy is especially applicable in the management of distal tibial fractures owing to the vulnerable extraosseous - metaphyseal blood supply in the distal region of tibia. ${ }^{8}$

\section{Aim of study}

The aim of the study was to evaluate the functional and radiological results and the complications associated with fixation of distal tibial fracture with MIPPO technique using distal tibial locking compression plate (DTLCP).

\section{METHODS}

\section{Study design and sampling}

From June 2018 to June 2019, a prospective study was done comprising of 25 patients admitted to KR Hospital, attached to Mysore Medical College and Research Institute, Mysore.

\section{Inclusion criteria}

Patients above 18 years and fractures coming under Arbeitsgemeinschaft für Osteosynthesefragen (AO) classification distal tibia fractures -43A1,43A2,43A3 were included.

\section{Exclusion criteria}

Patient less than 18 years, fractures coming under Gustillo Anderson III open fractures, associated vascular injuries, pathological fractures, compartment syndrome, intraarticular fractures were excluded.

After stabilizing the traumatized patient, routine preoperative evaluation was done including antero-posterior and lateral radiograph of the involved leg was obtained and the fracture was classified using AO foundation or orthopaedic trauma association classification. The leg was immobilized with above knee slab until the skin condition was favorable for surgery as evidenced by appearance of wrinkle sign. Patients with precarious skin condition were managed with limb elevation, regular dressing care and prophylactic IV antibiotics.
All cases were taken for primary fixation with LCP except 3 cases which were delayed due to swelling and those cases were operated after appearance of wrinkle sign.

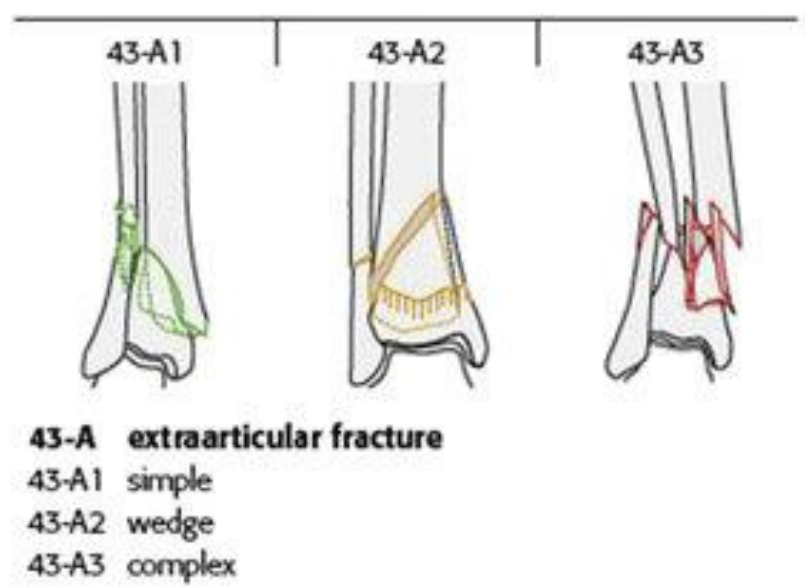

\section{Figure 1: AO classification of extra articular distal} tibia fractures.

\section{Surgical technique}

Patient put in supine position and prepared after application of pneumatic tourniquet. Medial approach is used. $5 \mathrm{~cm}$ curved skin incision put on medial aspect of distal tibia from the tip of medial malleolusto proximally. Incision deepened in same plane. Great saphenous vein and nerve are held identified and protected. Plate is inserted from distal to proximal on anteromedial surface using drill sleeve as plate manipulater without stripping the periosteum. Plate is first adjusted to periarticular area and locking screws inserted in one of the distal holes just above ankle joint approximating the plate to bone which and then Using another drill sleeve as manipulator at proximal end the plate is fixed using locking cortical screw. Rest of the screws are inserted under $\mathrm{c}$ arm guidance using stab incisions. Incision closed.

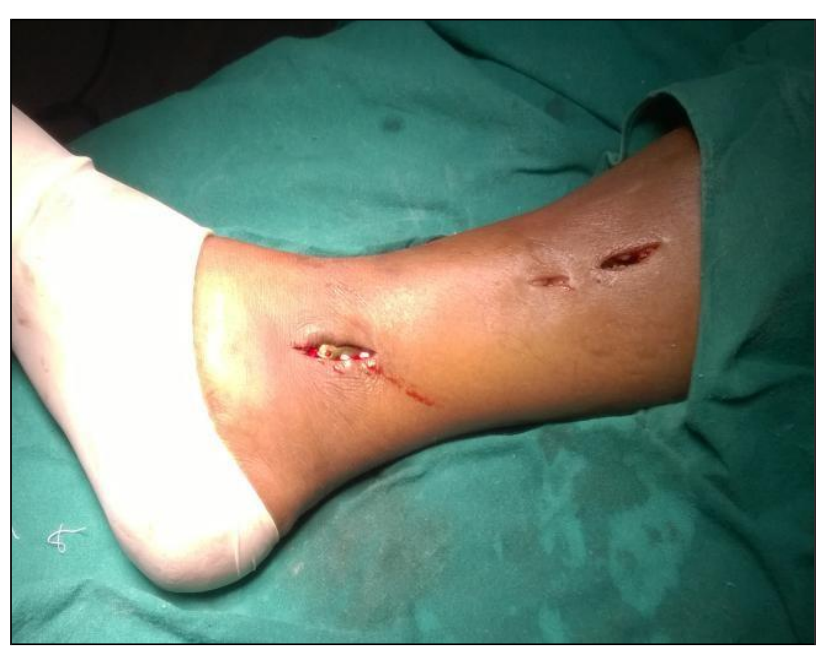

Figure 2: The incision over the medial malleoli. 


\section{Post-operative regimen}

Non-weight bearing of the patient and ankle range of movement exercises was done from the first postoperative day. Intravenous antibiotic regimen was continued for 3 days after the surgery. At 10th to 12th post operative day suture removal was done.

\section{Follow up}

The patients were followed up at intervals of, 4 weeks, 12 weeks, 18 weeks, 24 weeks, 12 months to assess the radiological union. After 6 weeks patient is allowed to partially bear weight. The fracture was designated as united, when there was periosteal bridging callus at the fracture site at least in three cortices in the anteroposterior and lateral views. Patient were allowed to bear weight according to radiological union and consolidation at fracture site. Patients were assessed at the end of follow up period according to the American orthopedic foot and ankle score scoring system.

\section{RESULTS}

All patients were judiciously followed up and evaluated clinically and radiologically till 12 months or till fracture union whichever came first. All the fractures united with an average of 17 weeks. There were 2 delayed union with 20 weeks signs of radiological callus formation.

In our study 25 patients with distal tibia extra-articular fracture were surgically managed with closed reduction and internal fixation using MIPPO technique with DTLCP.

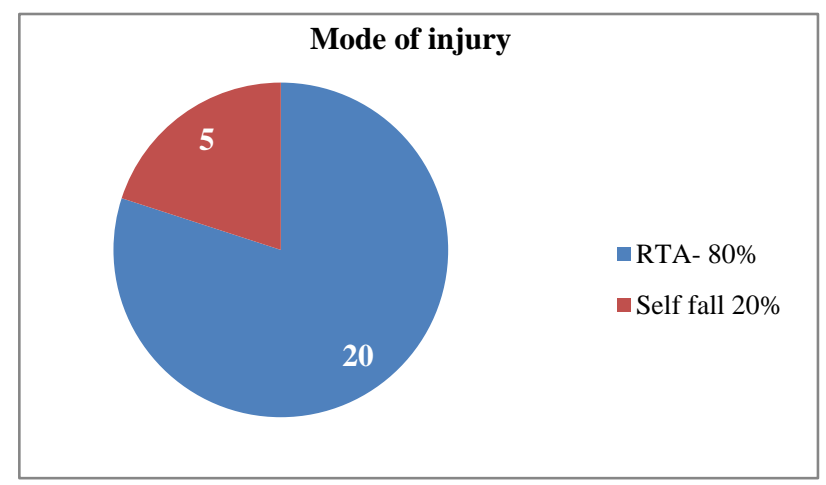

Figure 3: Mode of injury.

$80 \%$ of the patients sustained injury due to road traffic accidents in our study.

Table 1: Time of arrival and surgery.

\begin{tabular}{|lll|}
\hline Duration & No. of patients & Percentage $(\%)$ \\
\hline$<$ 2 days & 9 & 36 \\
\hline 2-7 days & 10 & 40 \\
\hline$>$ 7 days & 6 & 24 \\
\hline
\end{tabular}

Majority of the patients were operated between 2 to 7 days after admission in our study.

Majority of the fractured belonged to $43 \mathrm{~A} 1$ category in our study.

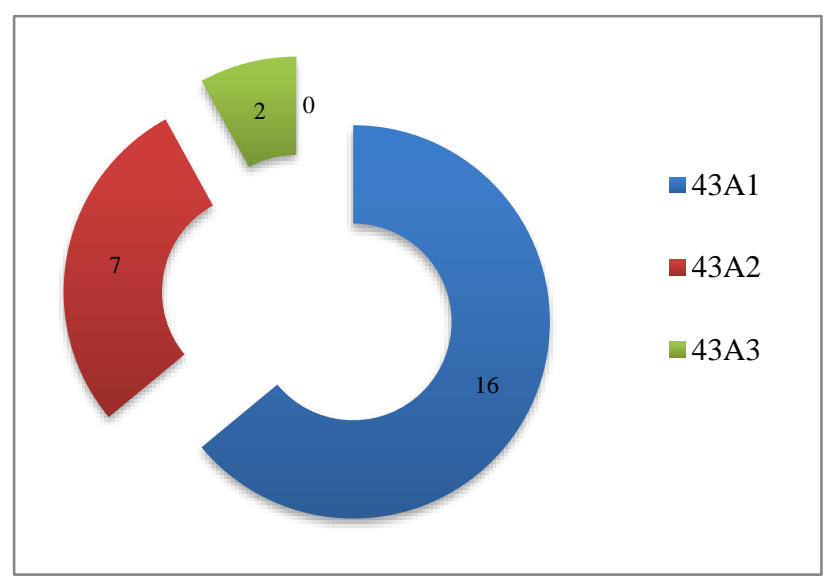

Figure 4: Fracture distribution according to AO/OTA classification.

Table 2: Radiological union.

\begin{tabular}{|lll|}
\hline $\begin{array}{l}\text { Duration } \\
\text { (in weeks) }\end{array}$ & No. of patients & Percentage $(\%)$ \\
\hline $\mathbf{1 4}$ & 10 & 40 \\
\hline $\mathbf{1 6}$ & 6 & 24 \\
\hline $\mathbf{1 8}$ & 6 & 24 \\
\hline $\mathbf{2 0}$ & 3 & 12 \\
\hline Total & 25 & 100 \\
\hline
\end{tabular}

Fractures of $10(40 \%)$ patients united in 14 weeks, 6 (24\%) patients united in 16 weeks, $6(24 \%)$ patients united in 18 weeks and $3(12 \%)$ patients united in 20 weeks. All cases fibula fracture healed without complication.

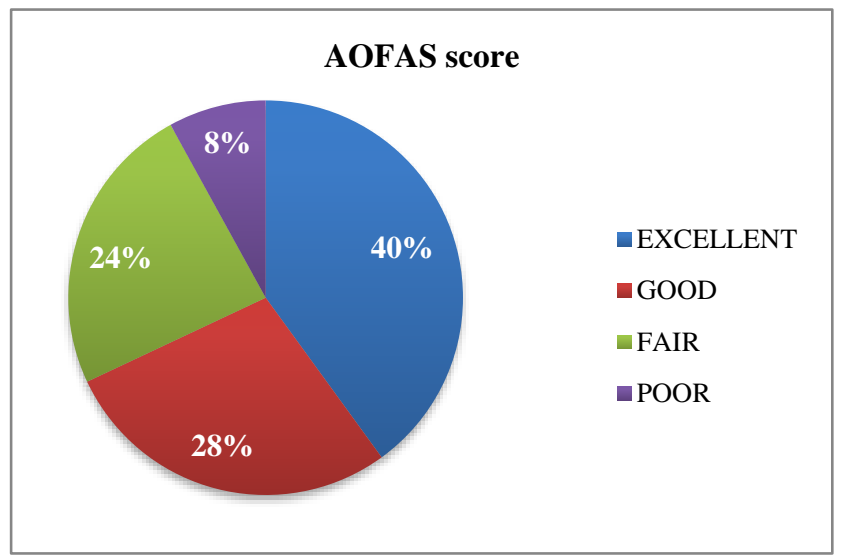

Figure 5: Functional outcome.

The average functional score in our study was $88.2 \%$. 

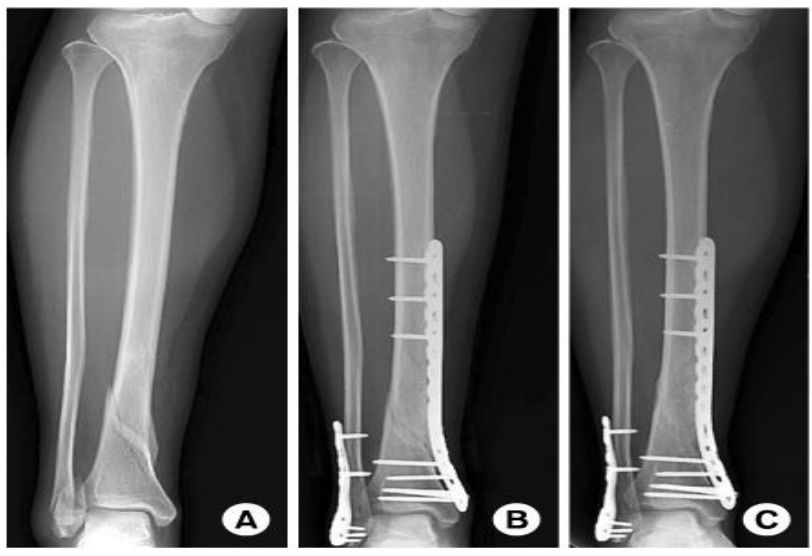

Figure 6: (A) Pre op X-ray, (B) immediate post op Xray, (C) post of $X$-ray of radiological union at 14 weeks.
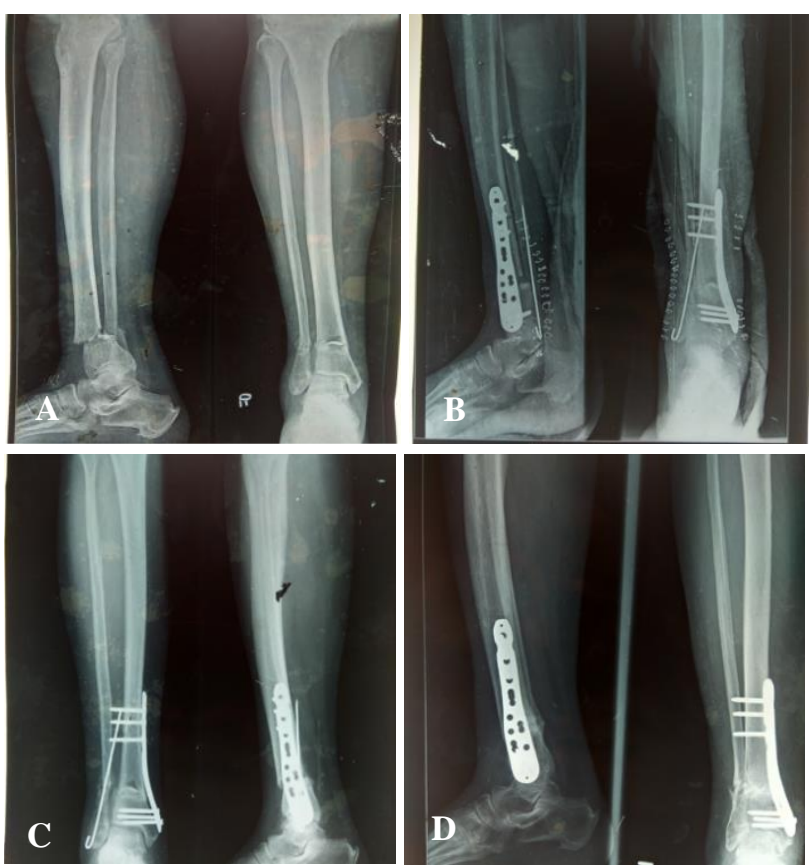

Figure 7: (A) Pre op X-ray, (B) immediate post op Xray, (C) post op X-ray at 6 weeks, (D) post of X-ray of radiological union at 14 weeks.

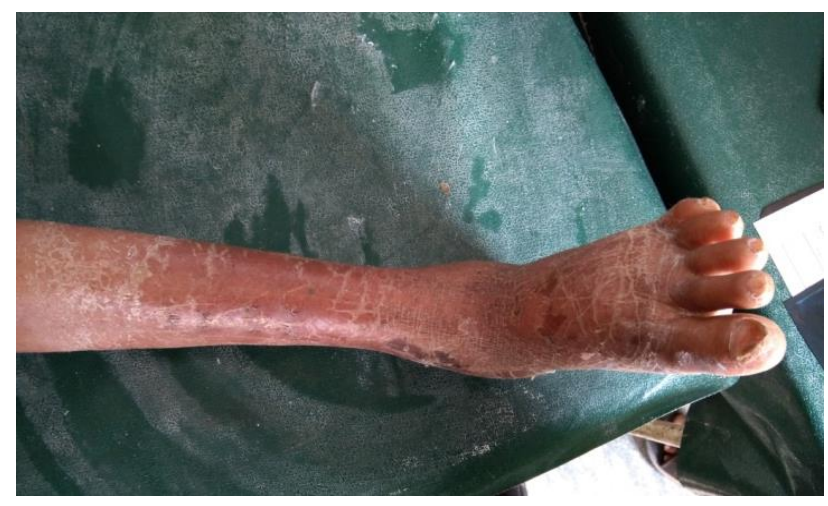

Figure 8: Complete plantar flexion at 14 weeks.
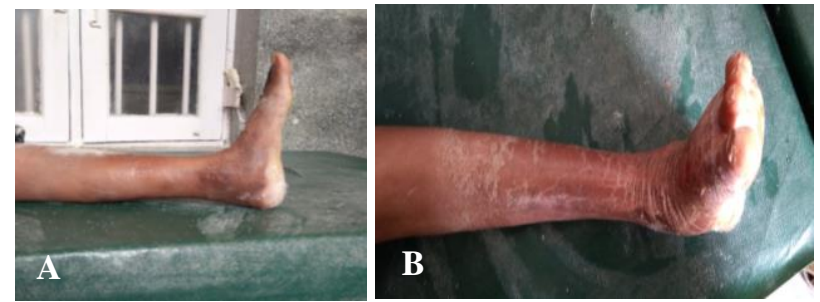

Figure 9 (A and B): Complete dorsiflexion at 14 weeks.

\section{DISCUSSION}

Distal tibial fractures at metaphysis- diaphysis junction with or without intra-articular extension is one of the difficult fractures to manage. Distal tibia has got circular cross sectional area with thinner cortex as compare to triangular diaphysis with thicker cortex. ${ }^{9}$

Open reduction internal fixation with conventional plateis not an ideal option because it involves srtipping of periosteum and since tibia is subcutaneous in that region around 2/3rd of blood supply is from periosteum. Nonunion, delayed union and infection are reported with the range of 8.3 to $35 \%$ and 8.3 to $25 \% 1$ respectively with ORIF with open plating. ${ }^{10}$

With the development of technique of MIPPO with LCP, which preserve extra osseous blood supply, respect osteogenic fracture hematoma, biologically friendly and stable fixation method is available for distal diametaphyseal tibia fracture. Unlike conventional plates, LCP is a friction independent self-stable construct, which provides both angular and axial stability and minimizes risk of secondary loss of reduction through a threaded interface between the screw heads and the plate body.

Cheng et al in paired comparison (15 in each group) of MIPPO and open technique with LCP found former is not statistically better in terms of union time (16.8 vs., 19.2 wks. $\mathrm{p}=0.737)$, recovery time to return to work (21.1 vs. 27.7 weeks, $\mathrm{p}=0.35$ ) and functional results. ${ }^{11}$ Kao et al found no statistically significant advantages of LCP over conventional plate group. ${ }^{12}$

Our study is a prospective study of cases of distal tibia fractures treated with MIPPO using distal tibial LCP. We did medial plating in all cases. The age group of our patients varied from 20 to 50 years with mean age of 35 years. 16 patients were male and the rest 9 were female patients. 17 cases involved right side and the rest 8 left side. This is comparitive to the study done by Borg et al and Mafulli et al. ${ }^{13,14}$ In our study male predominantly were affected which is comparitive to studies done by Mafulli et al and Guo et al. ${ }^{14,15}$

All the fractures united with an average of 17 weeks which was comparable with the study by Collinge et al (21 weeks) and Mushtaq et al (22 weeks). ${ }^{16,17}$ The 
functional score in our study was $88.2 \%$ which was comparable to studies conducted by Collinge et al and Ali et al. ${ }^{16,18}$

\section{Complications}

$12 \%$ of patients developed superficial skin infection which was treated with intravenous antibiotics. $8 \%$ of patients developed varus malalignment, $4 \%$ of patients developed ankle stiffness, $4 \%$ of patients developed limb length discrepancy. $4 \%$ of patients developed deep skin infection for which implant removal was done and treated with external fixation. Nonunion was not seen in any of our cases.

\section{CONCLUSION}

In our study 25 patients with distal tibia fracture had undergone closed reduction through MIPPO technique using distal tibia anatomical locking compression plates. This technique has resulted in the effective stabilization of these fractures and allows early range of motion at ankle joint. MIPPO technique decreases the incidence of on union and need for bone grafting since it provides good bone healing. MIPPO technique should be used in distal tibia fractures like fractures with small distal metaphyseal fragments, vertical splits, markedly comminuted fractures where intra medullary nailing cannot be done.

\section{Funding: No funding sources}

Conflict of interest: None declared

Ethical approval: The study was approved by the institutional ethics committee

\section{REFERENCES}

1. Michael Sirkin, Roy Sanders. The treatment of pilon fractures. Clinic Orto. 2001;32(1):91-102.

2. Russell TA. Fractures of the tibia and fibula. In: Rockwood CA, Green DP, Buckolz RW, Heckman JD, editors. Fractures in adults. 4th ed. Philadelphia: Lippincott; 1996: 2139-2157.

3. Bedi A, Le TT, Karunakar MA. Surgical Treatment of Nonarticular Distal Tibia Fractures. J Am Acad Orthop Surg. 2006;14(7):406-16.

4. Shrestha D, Acharya BM, Shrestha PM. Minimal invasive plate osteosynthesis with locking compression plate for distal diametaphyseal tibia fracture. Kathmandu Univ Med J. 2011;34(2):62-8.

5. Egol KA, Kubiak EN, Fulkerson E, Kummer FJ, Koval KJ. Biomechanics of locked plates and screws. J Orthop Trauma. 2004;18:488-93.

6. Kaab MJ, Frenk A, Schmeling A, Schaser K, Schutz M, Haas NP. Locked internal fixator: sensitivity of screw/plate stability to the correct Insertion angle of the screw. J Orthop Trauma. 2004;18:483-7.
7. Farouk O, Krettek C, Miclau T, Schandelmaier P, Guy P, Tscherne H. Minimally invasive plate osteosynthesis and vascularity: preliminary results of a cadaveric injection study. Injury. 1999;30:591-8.

8. Borelli J, Prickett W, Song E, Becker D, Ricci W. Extra osseous blood supply of the tibia and the effects of different plating techniques: human cadaveric study. J Orthop Trauma. 2002;16:691-5.

9. Im GI, Tae SK. Distal metaphyseal fractures of tibia a prospective Randomized trial of closed reduction and intramedullary nail versus open Reduction and plate and screws fixation. $J$ Trauma. 2005;59(5):1219-23.

10. Paluvadi SV, Lal H, Mittal D. Management of fractures of the distal third tibia by minimally invasive plate osteosynthesis - a prospective series of 50 patients. J Clin Orthop Trauma. 2014;5(3):129-36.

11. Cheng W, Li Y, Manyi W. Comparison study of two surgical options for distal tibia fracture-minimally invasive plate osteosynthesis vs. open reduction and internal fixation. Int Orthop (SICOT). 2011;35:737-42.

12. Kao FC, Tu YK, Hsu KY, Wu CH, Yen Cy, Chou MC. Treatment of distal tibial fractures by minimally invasive percutaneous plate osteosynthesis of three different plates: Results and cost-effectiveness analysis. Formosan J Musculoskeletal Dis. 2010;1:35-40.

13. Borg T, Larsson S, Lindsjo U. Percutaneous plating of distal tibial fractures. Preliminary results in 21 patients. Injury. 2004;35:608-14.

14. Maffulli N, Toms AD, McMurtie A, Oliva F. Percutaneous plating of distal tibial fractures. Int Orthop. 2004;28:159-62.

15. Guo JJ, Tang N, Yang HL, Tang TS. A prospective, randomised trial comparing closed intramedullary nailing with percutaneous plating in the treatment of distal metaphyseal fractures of the tibia. J Bone Joint Surg Br. 2010;92:984-8.

16. Cory Collinge MD, Mark Kuper DO, Kirk Larson, RNFA, and Robert Protzman MD. Minimally Invasive Plating of High-Energy Metaphyseal Distal Tibial Fractures. J Orthop Trauma. 2007;21:355-61.

17. Mustaq A, Shahid R, Asif M, Maqsood M. Distal Tibial fracture fixation with locking compression plate (LCP) using minimally invasive percutaneous osteosynthesis (MIPO) technique. Eur J Trauma Emerg Surg. 2008;35(2):159-64.

18. Ali SKI, Ravikumar K, Sheth S, Sinha AK, Karale A, Swamy MKS. Evaluation of the functional outcome in distal tibia fractures managed by MIPPO technique using distal tibia locking plate. Int $\mathbf{J}$ Orthop Sci. 2017;3(2):441-4.

Cite this article as: Shobha HP, Karthik S, Dhanda A, Lingaraju K, Kumar G. Functional and radiological outcome of surgical treatment of distal tibial fracture by minimally invasive percutaneous plate osteosynthesis technique. Int J Res Orthop 2020;6:340-4. 